NASA Technical Memorandum 105728

P.9

\title{
Neutron, Gamma Ray, and Temperature Effects on the Electrical Characteristics of Thyristors
}

\author{
A.J. Frasca \\ Wittenberg University \\ Springfield, Ohio \\ and \\ G.E. Schwarze \\ Lewis Research Center \\ Cleveland, Ohio
}

Prepared for the

27th Intersociety Energy Conversion Engineering Conference

cosponsored by the SAE, ACS, AIAA, ASME, IEEE, AIChE, and ANS

San Diego, California, August 3-7, 1992

\section{N/Sก}

$$
\begin{aligned}
& (\because A 3 A-1 *-1057 ? B) \text { UTURON, SAMMA OAY, ANO } \\
& \text { IEMLLATUR E FFCTS JN THE TLFCTRICAL } \\
& \text { CIAAACTERSTICS JF THYRISTUOS (NASA) a D }
\end{aligned}
$$




\section{NEUTRON, GAMMA RAY, AND TEMPERATURE EFFECTS ON THE ELECTRICAL CHARACTERISTICS OF THYRISTORS}

\author{
A. J. Frasca \\ Wittenberg University \\ Springfield, Ohio
}

\author{
G. E. Schwarze \\ National Aeronautics and Space Administration \\ Lewis Research Center \\ Cleveland, Ohio
}

\section{ABSTRACT}

Experimental data showing the effects of neutrons, gamma rays, and temperature on the electrical and switching characteristics of phase-control and inverter-type SCRs are presented. The special test fixture built for mounting, heating, and instrumenting the test devices is described. Four SCRs were neutron irradiated at $300 \mathrm{~K}$ and four at 365 $\mathrm{K}$ for fluences up to $3.2 \times 10^{13} \mathrm{n} / \mathrm{cm}^{2}$, and eight were gamma irradiated at $300 \mathrm{~K}$ only for gamma doses up to 5.1 Mrads. The electrical measurements were made during irradiation and the switching measurements were made only before and after irradiation. Radiation induced crystal defects, resulting primarily from fast neutrons, caused the reduction of minority carrier lifetime through the generation of $R-G$ centers. The reduction in lifetime caused increases in the on-state voltage drop and in the reverse and forward leakage currents, and decreases in the turn-off time.

\section{INTRODUCTION}

The electrical components used in the power conversion, power conditioning, and instrument and control subsystems of space nuclear power systems must meet high performance and reliability requirements while being subjected to high levels of neutrons and gamma rays, and possibly high temperatures. The location of the electrical components and the allowable shielding mass budget will determine the level of radiation tolerance required by these components. Development of electrical components with high radiation tolerance will reduce shielding mass and development of electrical components with high temperature tolerance will reduce radiator size and mass. Thus, characterization data of electrical components describing the effects of high nuclear radiation and temperature environments is required by the electrical circuit designer.

The effects of neutrons, gamma rays, and post-irradiation thermal annealing on the electrical characteristics of power Bipolar Junction Transistors (BJTs), Metal-OxideSemiconductor Field Effect Transistors (MOSFETs), and Static Induction Transistors (SITs) were previously reported $(1,2)$. This paper will discuss the experimental results obtained for phase-control and inverter-type Silicon Controlled Rectifiers (SCRs) which are members of the thyristor family. The devices reported in this paper were neutron irradiated in-situ at 300 and $365 \mathrm{~K}$. In separate experiments, new devices of the same type were gamma irradiated at 300 $\mathbf{K}$ only. A brief discussion will first be given of thyristor characteristics, and the effects of neutrons and gamma rays on semiconductor materials.

\section{THYRISTOR CHARACTERISTICS}

A four layer device with alternate pnpn semiconducting regions and with only an anode and cathode electrode is called a pnpn diode. The addition of a gate electrode to the pnpn diode gives a three terminal device called a thyristor which is a bipolar device since both electrons and holes participate in the current transport process. The thyristor is a family of devices which includes the SCR. The SCR is generally divided into two categorics: the converter or phase control SCR which is designed for the lowest on-state voltage $V_{F}$, but has a long turn-on time $t_{q}$, and the inverter or fast switching SCR which has a lower $t_{q}$ but a higher $V_{F}$ than the converter SCR. Compared to the MOSFET, SIT, BJT, and IGBT, the SCR is an inherently slow switch because of the long time required to remove the stored charge after conduction.

The main electrical and switching parameters which characterize the SCR are forward and reverse voltage blocking ratings, steady state conduction and surge current, on-state voltage drop, turn-on and turn-off times, rate of rise of conduction current, and rate of rise of forward voltage. The SCR has four distinct states or operating modes and the sequence is off-state, turn-on, on-state, and turn-off. These states are not independent of each other because operational interrelations exist between them.

The static I-V characteristics of the SCR are shown in Figure 1. The SCR's reverse I-V characteristic has only the reverse voltage blocking state as shown by curve $A B$ with curve $B C$ showing the avalanche breakdown. The SCR's forward I-V characteristics has two stable states: the forward voltage blocking state shown as curve $A D$ where $V_{B O}$ is the forward breakover voltage, and the forward 
conduction state shown as curve FG. The state between the two stable states, shown as curve EF, is unstable and is characterized by a negative resistance. Thus, the SCR has bipolar voltage withstanding capability, but unidirectional conduction current capability, and has controlled turn-on but uncontrolled turn-off.

The basic SCR structure, as shown in Figure 2 a consists of an anode, cathode, and gate contacts, and three pnjunctions: the anode junction $\mathrm{J} 1$, the center junction $\mathrm{J} 2$, and the cathode junction J3. The SCR can be represented as two overlapping or complementary BJTs as shown in Figure 2: the P1N1P2 layers form a pnp transistor $Q 1$, and the N2P2N1 layers form an npn transistor Q2. For reverse voltage blocking, $\mathrm{J} 2$ is forward biased, and $\mathrm{J} 1$ and $\mathrm{J} 3$ are reverse-biased with $\mathrm{J} 1$ supporting almost the entire applied voltage. For forward voltage blocking J1 and J3 are forward-biased and $\mathrm{J} 2$ is reverse-biased and it supports the applied forward voltage. For the on-state condition, J1, J2, and $\mathrm{J} 3$ are all forward-biased. For this condition both Q1 and $\mathrm{Q} 2$ operate in the saturation region of the $\mathrm{I}-\mathrm{V}$ common emitter transistor curve.

The minority carrier lifetime is the average time a minority carrier lives in a sea of majority carriers before it recombines with a majority carrier. In thyristor design the control of lifetime is one of the most important parameters because it influences the trade-offs made in leakage current, on-state voltage, and turn-off time.

The leakage current has a diffusion current component due to thermally generated electron-hole pairs within a diffusion length of the reverse biased depletion region edges, and a generation current component due to thermally generated electron-hole pairs caused by recombinationgeneration (R-G) centers in the depletion regions. The leakage current increases for an increase in temperature and a decrease in minority carrier lifetime. The anode current $I_{A}$ for the forward-biased condition is readily derived from an analysis of the transistor equivalent circuit in Figure $2 b$ and basic transistor physics,

$$
I_{A}=\frac{\alpha_{2} I_{G}+I_{C B O I}+I_{C B O 2}}{1-\left(\alpha_{1}+\alpha_{2}\right)}
$$

where

$\mathrm{I}_{\mathrm{G}}=$ applied gate current,

$\mathrm{I}_{\mathrm{CBO} 1}, \mathrm{I}_{\mathrm{CBO} 2}=$ collector-base leakage currents of $\mathrm{Q} 1$ and Q2, respectively, for open emitters,

$\alpha_{1}, \alpha_{2}=$ common base current gain of $\mathrm{Q} 1$ and $\mathrm{Q} 2$, respectively.

Both $\alpha_{1}$ and $\alpha_{2}$ increase with current and this fact is the key to device turn-on as seen by Eq. (1). The increase in $\alpha_{1}$ and $\alpha_{2}$ through positive feedback such that $\left(\alpha_{1}+\alpha_{2}\right)=1$ establishes the regenerative action necessary to switch, and then sustain, the SCR in the forward conduction state.

In steady state conduction the SCR is very similar in operation to the $\mathrm{p}^{+}-\mathrm{i}-\mathrm{n}^{+}$diode with holes from the P1emitter (anode) flooding the N1-base and electrons from the
N2-emitter (cathode) flooding the P2-base. The voltage drop $V_{i}$ across the i-region of width $W$ is shown to be (3),

$$
V_{i}=\frac{W^{2}}{\left(\mu_{n}+\mu_{p}\right) \tau_{p}}
$$

where $\mu_{\mathrm{n}}$ and $\mu_{\mathrm{p}}$ are the electron and hole mobilities, respectively and $\tau_{p}$ is the minority (hole) carrier lifetime. Since $V_{F}$ is almost equal to $V_{j}$, then it is seen that a very wide $\mathrm{N} 1$ region, required for high voltage devices, gives a high $\mathrm{V}_{\mathrm{F}}$ and also, any decrease in $\mu_{\mathrm{n}}, \mu_{\mathrm{p}}$, or $\tau_{\mathrm{p}}$ will cause $\mathrm{V}_{\mathrm{F}}$ to increase.

Gate triggering is the most common means for SCR turn-on. A positive current pulse applied to the gate-cathode causes $\alpha_{2}$ to increase and thus, provides the means for turnon. The turn-on time is generally divided into three distinct intervals: turn-on delay, rise, and plasma spreading time. The turn-off is the reverse of the turn-on and it is the time $t_{q}$ required for the $S C R$ to recover its forward blocking capability after conduction and is often referred to as the commutating time. A decrease in minority carrier lifetime causes a decrease in $t_{q}$. During $t_{q}$ all the stored charge accumulated during on-state conduction must be removed through the processes of charge withdrawal and electronhole recombination.

\section{NEUTRON AND GAMMA RAY EFFECTS}

Only a very brief review of the important aspects of the effects of nuclear radiation on a semiconductor is possible in this paper. A more complete discussion of the effects of gamma rays, neutrons, and thermal annealing on the electrical properties of semiconductors can be found in reference 2 and the references cited therein. High-energy nuclear radiation incident on a semiconductor crystal is absorbed in the material by two mechanisms: atomic collisions and electronic ionization. The relative importance of the two mechanisms depends on the type of radiation and the type of semiconductor device.

Atomic collisions occur between the incident high energy particles and atoms of the crystal, and also subsequent collisions between the knock-on or recoiling atoms and other atoms of the crystal. The mechanism of collisions results in atomic displacement damage if the recoiling atom receives sufficient energy to be displaced from its equilibrium site in the crystal lattice. Atomic disorder or displacement damage causes the formation of simple defects such as vacancy - interstitial pairs, or more complex defects known as "clusters" which are isolated regions in the lattice structure containing large quantities of displaced atoms. The displacement damage is dependent on the type, energy, direction, and quantity of the incident particles; type and concentration of defects and impurities existing in the crystal prior to irradiation; and irradiation conditions such as crystal temperature.

The radiation induced defects caused by displacement 
of atoms affects the electrical properties of the semiconductor by the formation of energy levels in the intrinsic semiconductor's energy bandgap. Shallow induced energy levels will act as donors or acceptors depending on how close these levels are to either the conduction or valence band. Deep energy levels will act as recombination-generation ( $R$ G) centers and are sometimes called deep level traps.

The introduction of R-G centers in a semiconductor introduces an additional mechanism to reduce the lifetime of a minority carrier wandering about in majority carrier territory. An increase in radiation induced defects causes an increase in R-G center density and this causes a decrease in minority carrier lifetime and an increase in the R-G rates. Radiation damage caused by atomic displacements also alters the periodicity of the crystal lattice, and the displaced atoms act as carrier scattering centers to cause a decrease in carrier mobility.

The interaction of epicadmium neutrons $(0.5 \mathrm{eV}$ to 10 $\mathrm{MeV}$ ) with a semiconductor material is primarily by collisions between the nucleus of an atom and the neutron, and subsequent collisions caused by the recoiling atoms. Thus, neutrons primarily cause displacement damage that alters the semiconductor's bulk electrical properties, which includes minority carrier lifetime, carrier mobility, and carrier concentration. Fast neutrons also cause ionization but their predominant effect in semiconductor materials is their collisions with atomic nuclei to cause atom displacement.

The interaction of energetic gamma rays with a semiconductor material is primarily by Compton scattering that causes ionization of the material's atoms. Ionization causes either excitation of orbital electrons or the production of electron-hole pairs. An ionized electron imparted with sufficient kinetic energy can cause either additional ionization, or impart sufficient energy to an atom to cause its displacement. Energetic gamma rays can generate R-G centers through displacement effects but not as efficiently as fast neutrons.

\section{EXPERIMENTAL SETUP}

The research facilities and test equipment of the NASA Lewis Research Center, Wittenberg University, Ohio State University (OSU), and the University of Cincinnati (UC) are used for the experimental tests, data analysis, and radiation damage assessment. The OSU Research Nuclear Reactor is used for the neutron tests and the peak in the reactor's neutron energy spectrum is near $2 \mathrm{MeV}$. The UC Cobalt-60 facility is used for the gamma ray tests and this facility consists of a large water pool with the source located about fifteen feet below the water surface. The use of a submerged Cobalt -60 source allows for a significant amount of gamma backscatter which gives a broadened energy spectrum typical of the energy of fission fragment decay gamma rays.

A key component needed in the performance of in-situ radiation tests is the test fixture used to mount, heat, and instrument the test devices. The test fixture built to test the
SCRs was designed primarily for use in the six-inch diameter beam part of the OSU Reactor. The fixture was fabricated from a five-inch diameter by nine-inch long thin-wall cylindrical shell and end plates made of aluminum. The exterior of the fixture is shrouded with cadmium to absorb thermal neutrons and thus, reduce nuclear activation of the internal contents. The interior structure consists of four mounting assemblies fastened to the interior walls of the cylinder. Each assembly is fabricated from a bracket made of fiberglass board to which an aluminum heat sink mounting plate is bonded. A resistive heating element and platinum temperature sensor are bonded to each aluminum plate. A separate, external temperature controller and power supply module is used to heat, measure, and control the temperature of each aluminum mounting plate to within a few degrees $K$. A single test device with a high voltage dielectric spacer is mounted to each aluminum plate in such a manner that maximum thermal contact is made between the device and plate to ensure uniform heating of the device. A regulated flow of cold air from an external source can be forced through the fixture to control the temperature of those devices which require no heating. Both power and sense cables are provided for each test device and these cables extend outside the radiation source to the test and control instruments.

\section{TEST DESCRIPTION}

The electrical characterization of the SCRs was done in-situ for neutron irradiations at 300 and $365 \mathrm{~K}$, and for gamma irradiation at $300 \mathrm{~K}$ only. A curve tracer was used to measure the static characteristics of the SCRs before, during, and after irradiation. The dynamic (switching) tests were done only before and after irradiation because of the capacitance and inductance effects introduced by the long (15 foot) signal and power cable used between the test instruments and the test fixture located in the radiation source.

Both phase-control and inverter-type SCRs were tested. The phase-control SCR was a C38E and rated by the manufacturer as follows: peak repetitive forward $V_{D R M}$ and reverse $V_{R R M}$ blocking voltage of $500 \mathrm{~V}$, maximum continuous RMS on-state current $I_{\text {TRMS }}$ of $35 \mathrm{~A}$, maximum on-state peak voltage $V_{T M}$ of $2 \mathrm{~V}$ at $50 \mathrm{~A}$ peak and junction temperature $\mathrm{Tj}$ of $25 \mathrm{C}$, and maximum turn-off time $\left(\mathrm{t}_{\mathrm{g}}\right)_{\mathrm{M}}$ of $24 \mu \mathrm{s}$ at $T \mathbf{j}=150 \mathrm{C}$. The inverter-type SCR was a 20RIF40W20 and rated by the manufacturer as follows: $V_{\text {DRM }}=V_{\text {RRM }}$ $=400 \mathrm{~V}, \mathrm{I}_{\mathrm{TRMS}}=32 \mathrm{~A}, \mathrm{~V}_{\mathrm{TM}}=2 \mathrm{~V}$ at $63 \mathrm{~A}$ and $\mathrm{Tj}=25$ $\mathrm{C}$, and $\left(\mathrm{t}_{\mathrm{q}}\right)_{\mathrm{M}}=20 \mu \mathrm{s}$ at $\mathrm{Tj}=125 \mathrm{C}$.

Four phase-control SCRs were neutron irradiated in one test run and four inverter-type SCRs were neutron irradiated in another test run. The placement of the SCRs in the test fixture for the neutron tests were as follows: Devices \#1 and \#2 (pair B) were mounted in the same plane and subjected to approximately the same epicadmium neutron flux with one device held at $300 \mathrm{~K}$ and the other at $365 \mathrm{~K}$. Devices \#3 and \#4 (pair A) were mounted in a 
plane forward of pair B and were subjected to a flux approximately $60 \%$ greater than those in pair $B$. One device of pair B was at $300 \mathrm{~K}$ and the other at $365 \mathrm{~K}$.

The C38E pair $A$ devices were irradiated to a fluence of $2.6 \times 10^{13} \mathrm{n} / \mathrm{cm}^{2}$ after which both devices failed, and the pair $B$ devices were irradiated to $3.1 \times 10^{13} \mathrm{n} / \mathrm{cm}^{2}$ without failure. The 20RIF40W20 pair A devices were irradiated to $3.2 \times 10^{13} \mathrm{n} / \mathrm{cm}^{2}$ and pair $B$ to $1.9 \times 10^{13} \mathrm{n} / \mathrm{cm}^{2}$. None of the 20RIF40W20 devices failed during irradiation.

Two gamma irradiation tests were conducted at $300 \mathrm{~K}$ only. In the first test, two C38Es and two 20RIF40W20s were gamma irradiated at a dose rate of $67.3 \mathrm{krads} / \mathrm{hrs}$ for a total dose of 0.52 Mrads. In the second test run new C38Es and 20RIF40W20s were again gamma irradiated at a dose rate of $67.3 \mathrm{krads} / \mathrm{hr}$ but for almost 10-times longer to give a total dose of $5.1 \mathrm{Mrad}$.

\section{TEST RESULTS AND DISCUSSION}

The combined effects of epicadmium neutrons and temperature on $V_{F}$ at a conduction current of $25 \mathrm{~A}$ are shown in Figure 3 for the phase-control SCRs, and in Figure 4 for the inverter-type SCRs. A comparison of the results plotted in these two figures shows the following. First, for both types of SCRs, the devices irradiated at $365 \mathrm{~K}$ show no significant difference in the $\mathrm{V}_{\mathrm{F}}$ characteristics compared to those irradiated at $300 \mathrm{~K}$. These results would indicate that the radiation induced defects are permanent, and that temperatures up to $365 \mathrm{~K}$ do not promote thermal annealing of the radiation damage. Second, the plots show that the shape of the $V_{F}$ versus fluence curve is nearly identical for both types of devices. Both curves show that $V_{F}$ increases only slightly for fluences up to $10^{12} \mathrm{n} / \mathrm{cm}^{2}$, increases at a faster rate between $10^{12}$ and $10^{13} \mathrm{n} / \mathrm{cm}^{2}$, and increases sharply beyond $10^{13} \mathrm{n} / \mathrm{cm}^{2}$. The behavior of the on-state forward I-V characteristic curves, as displayed on the curve tracer screen, progressively became more jittery and unstable as the fluence increased above $10^{13} \mathrm{n} / \mathrm{cm}^{2}$ for both types of devices. Thus, fluences greater than $10^{13} \mathrm{n} / \mathrm{cm}^{2}$ not only cause a rapid increase in $V_{F}$, but also a rapid deterioration in the stability of the on-state I-V curves. An increase in fluence will cause an increase in the radiation induced R-G centers, and thus, a decrease in the minority carrier lifetime. Equation (2) shows an inverse relationship between $V_{F}$ and minority carrier lifetime. Based on this relationship, it is concluded that the most probable cause for the increase in $V_{F}$ for increasing fluence is the decrease in minority carrier lifetimes in the N1- and P2- bases of the SCR.

Figures 5 and 6 show the effects of epicadmium neutrons and temperature on the gate triggering voltage $\mathrm{V}_{\mathrm{GP}}$ as a function of fluence. The results plotted in these figures show that the inverter-type SCRs have a slightly higher $V_{G F}$ at $300 \mathrm{~K}$ than at $365 \mathrm{~K}$ for all fluence levels, while the phasecontrol SCRs have the same $\mathrm{V}_{\mathrm{GF}}$ for both temperatures up to about a fluence of $3 \times 10^{12} \mathrm{n} / \mathrm{cm}^{2}$, after which the $V_{\mathrm{GF}}$ for the $300 \mathrm{~K}$ devices becomes somewhat higher. The results also show that $\mathrm{V}_{\mathrm{GF}}$ for both types of devices is not greatly affected until a fluence of $10^{13} \mathrm{n} / \mathrm{cm}^{2}$ is reached when $V_{G F}$ begins to increase. This increase is especially noticeable for the phase-control SCRs which shows $\mathrm{V}_{\mathrm{GF}}$ increasing sharply at $10^{13} \mathrm{n} / \mathrm{cm}^{2}$ while the inverter-type SCRs show only a gradual increase in $\mathrm{V}_{\mathrm{GF}}$ at $10^{13} \mathrm{n} / \mathrm{cm}^{2}$. $A$ possible reason for the increase in $V_{\mathrm{GF}}$ for fluences beyond $10^{13} \mathrm{n} / \mathrm{cm}^{2}$ is that $\alpha_{2}$ becomes more sensitive to radiation damage in the N2P2-gate region at this fluence level, and as a result, $\alpha_{2}$ begins to decrease. If it is assumed that an increase in gate voltage causes an increase in gate current, then an analysis of Equation (1) shows that a decrease in $\alpha_{2}$ requires an increase in $\mathrm{V}_{\mathrm{GF}}$ for regenerative action to be established.

The pre- and post-irradiation reverse leakage current versus reverse voltage blocking curves for one of the phasecontrol and one of the inverter-type SCRs irradiated at 300 $K$ are shown in Figures 7 and 8 respectively. The postirradiation curves are for a fluence of about $3 \times 10^{13} \mathrm{n} / \mathrm{cm}^{2}$ and for both types of SCRs, the post-irradiation curves lie above their pre-irradiation curves. This ordering of the curves shows that the leakage current increases with fluence. This is an expected result because, as previously discussed, an increase in fluence generates more defects, and thus, more R-G centers to cause a decrease in minority carrier lifetime. Because leakage current and minority carrier lifetime have an inverse relationship, a decrease in lifetime will cause an increase in leakage current. The $300 \mathrm{~K}$ preand post-irradiation forward leakage current versus forward blocking voltage curves for these same devices gave the same type of curves as those shown in Figures 7 and 8.

The pre-and post-irradiation reverse leakage current versus reverse blocking voltage curves for one of the phasecontrol and one of the inverter-type SCRs irradiated at 365 $K$ are given in Figures 9 and 10, respectively. The postirradiation fluence was about $3 \times 10^{13} \mathrm{n} / \mathrm{cm}^{2}$. The pre-and post-irradiation leakage curves at $300 \mathrm{~K}$ for the inverter-type SCR irradiated at $365 \mathrm{~K}$ is included in Figure 10, but only the post-irradiation leakage curve at $300 \mathrm{~K}$ for the phasecontrol SCR irradiated at $365 \mathrm{~K}$ is included in Figure 10 because no pre-irradiation data was taken at $300 \mathrm{~K}$. However, based on the results given in Figure 7 , the $300 \mathrm{~K}$ preirradiation curve would lie below the post-irradiation curve. Thus, for both types of SCRs, both the 365 and $300 \mathrm{~K}$ postirradiation leakage curves lie above their respective preirradiation curves.

The leakage current is expected to be higher at $365 \mathrm{~K}$ then at $300 \mathrm{~K}$ because the number of intrinsic carriers increases exponentially with temperature and an increase in intrinsic carrier density causes an increase in leakage current. For both types of SCRs, the increase in the post-irradiation reverse leakage currents from their pre-irradiation values is almost always greater at $365 \mathrm{~K}$ than at $300 \mathrm{~K}$. Based on minority carrier lifetime arguments, it would be anticipated that the increase in post-irradiation leakage currents would be approximately the same for both temperatures. One possible reason for this difference might be the existence of leakage current paths external to the bulk semiconductor at 
$365 \mathrm{~K}$ but not at $300 \mathrm{~K}$. Additional experiments would need to be conducted to determine the cause of this observed difference. However, the results in Figures 9 and 10 would strongly indicate that irradiating the SCRs at $365 \mathrm{~K}$ did not cause any thermal annealing of the radiation induced defects at that temperature. Thus, irradiating the SCRs at $365 \mathrm{~K}$ appears to produce no beneficial effects, and in fact, appears to produce just the opposite effect.

Two devices for each type of SCR were gamma irradiated for gamma doses up to $5.1 \mathrm{Mrads}$ at $300 \mathrm{~K}$ only. For both types of SCRs, the increase in $V_{F}$ at 0.5 Mrads was negligible, and at $5.1 \mathrm{Mrads}, \mathrm{V}_{\mathrm{F}}$ increased less than a tenth of a volt over its pre-irradiation value. The effect of gamma rays on the off-state forward and reverse I-V characteristics are plotted for one of the phase-control SCRs in Figure 11 and for one of the inverter-type SCRs in Figure 12. In each figure the I-V characteristics are plotted for $0,1,3$, and 5 Mrads. A comparison of the set of curves in these figures shows that the breakover voltage points on the I-V curves for the phase-control SCR are much better defined than for the inverter type SCR. For both types of SCRs though, it is seen that both the forward and reverse voltage capability gradually decreases as the gamma dose increases. That is, the leakage current gradually increases with dose. Again, this increase in leakage current is attributed to a decrease in the minority carrier lifetime.

$t_{q}$ was measured for all the SCRs prior to irradiation. For the neutron irradiated SCRs, it was only possible to measure the post-irradiation $\mathrm{t}_{\mathrm{q}}$ of one phase-control and one inverter-type SCR. The other SCRs had failed either during or immediately after irradiation, or would not operate in the on-state after being turned-on. The surviving phase-control SCR, which had been irradiated to $3.1 \times 10^{13} \mathrm{n} / \mathrm{cm}^{2}$ at 365 $K$, had pre- and post-irradiation $t_{g}$ of 26.9 and $0.70 \mu \mathrm{s}$, respectively, to give almost a 40 -fold drop in $t_{q}$. The surviving inverter-type SCR, that had been irradiated to 1.9 $x 10^{13} \mathrm{n} / \mathrm{cm}^{2}$ at $365 \mathrm{~K}$, had a pre-and post-irradiation $\mathrm{t}_{\mathrm{g}}$ of 5.46 and $0.65 \mu \mathrm{s}$, respectively, to give almost a 9-fold decrease in $\mathrm{t}_{\mathrm{q}}$. The decrease in $\mathrm{t}_{\mathrm{q}}$ was caused by a decrease in minority carrier lifetime and these large reductions in the lifetime give a clear indication of the level of radiation damage inflicted on the semiconductor material's crystal lattice.

Although not as pronounced as the effects of neutrons on $t_{q}$, gamma ray dose levels at $5.1 \mathrm{Mrad}$ did cause noticeable decreases in $t_{q}$ with the slow speed phase-control SCR showing the largest change. The change in $t_{q}$ for the two phase-control SCRs was as follows: Pre-and post-irradiation $\mathrm{t}_{\mathrm{q}}$ for one device was 29.5 and $10.95 \mu \mathrm{s}$, respectively, $(62 \%$ decrease), and for the other device was 17.76 and $10.63 \mu \mathrm{s}$, respectively, (40\% decrease). For the inverter-type SCRs, $\mathrm{t}_{\mathrm{q}}$ changed as follows: Pre- and post-irradiation $t_{g}$ for one device was 6.06 and $4.42 \mu \mathrm{s}$, respectively, (27\% decrease), and for the other device, 5.42 and $4.03 \mu \mathrm{s}$, respectively, (25\% decrease). These decreases in $\mathrm{t}_{\mathrm{q}}$ clearly show that gamma rays are capable of displacing atoms from their lattice sites as evidenced by the reduction in minority carrier lifetime through the generation of R-G centers. The gamma irradiation results also clearly show that gamma rays are a very effective means to increase the switching speed of the phase-control SCRs without causing severe degradation of the $V_{F}$ and leakage current characteristics.

\section{CONCLUSIONS}

The most significant results from the experimental investigation of neutron and gamma irradiated SCRs are the following:

(1) Neutron fluences beyond $10^{13}$ caused $V_{F}$ to increase sharply regardless of irradiation temperature,

(2) the reverse and forward leakage currents increased at a faster rate at $365 \mathrm{~K}$ than at $300 \mathrm{~K}$. In this case, a higher irradiation temperature had a detrimental, rather than a beneficial effect,

(3) neutron fluences of $3 \times 10^{13} \mathrm{n} / \mathrm{cm}^{2}$ caused a 40 -fold decrease in $t_{q}$ of the phase-control SCR, and

(4) gamma ray doses up to 5.1 Mrads caused insignificant increases in $\mathrm{V}_{\mathrm{F}}$, small increases in leakage currents, and up to a $62 \%$ decrease in $t_{q}$ of the phase-control SCRs.

All these radiation induced changes in the SCR's characteristics are traceable to a reduction in the minority carrier lifetime. An increase in radiation induced defects caused by displacement of the lattice atoms, causes an increase in R-G centers, and a subsequent decrease in minority carrier lifetime. Increasing the radiation hardness of SCRs for neutron fluences greater than $10^{13} \mathrm{n} / \mathrm{cm}^{2}$ will require finding a means to reduce the deterioration of the minority carrier lifetime. Presently available radiation damage evidence would indicate a semiconductor material other than silicon will be required to accomplish that objective.

\section{REFERENCES}

1. Schwarze, G. E. and Frasca, A. J., "Neutron and Gamma Irradiation Effects on Power Semiconductor Switches" in Proc. of the 25th Intersociety Energy Conversion Engineering Conference, held in Reno, NV, August 12-17, 1990.

2. Schwarze, G. E. and Frasca, A. J., "Neutron, Gamma Ray and Post-Irradiation Thermal Annealing Effects on Power Semiconductor Switches," AIAA 91-3525, ALAA/NASA/OAI Conference on Advanced SEI Technolgies, September 4-6, 1991, Cleveland, OH

3. Taylor, Paul D., Thyristor Design and Realization. John Wiley \& Sons, 1987, pp 56-58. 


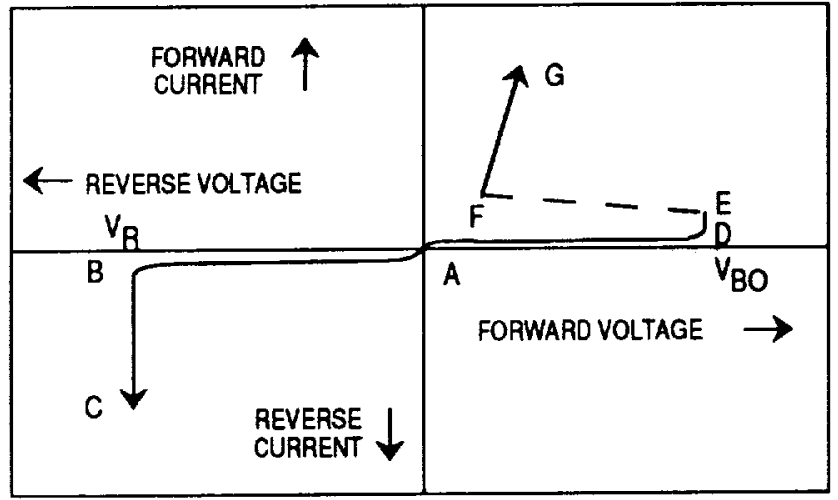

FIG. 1 - STATIC I-V CHARACTERISTICS FOA SCR.

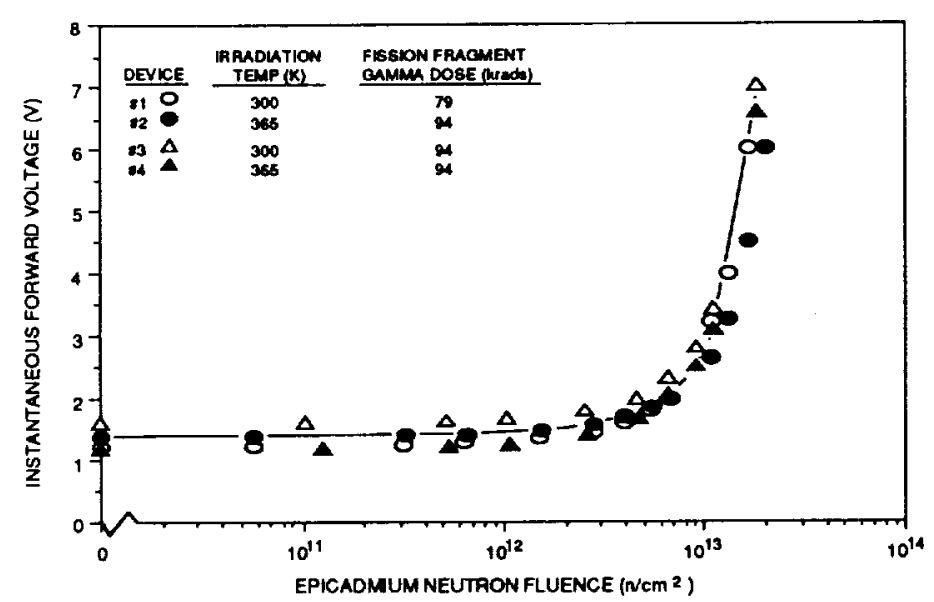

FIG 3. INSTANTANEOUS FORWARD VOLTAGE AT INSTANTANEOUS FORWARD CURRENT OF 25 A VERSUS EPICAOMUM NEUTRON FLUENCE FOR PHASE-CONTROL TYPE SILICON 25 A VERSUS EPICAOMIUM NEUTRON FLUENCE

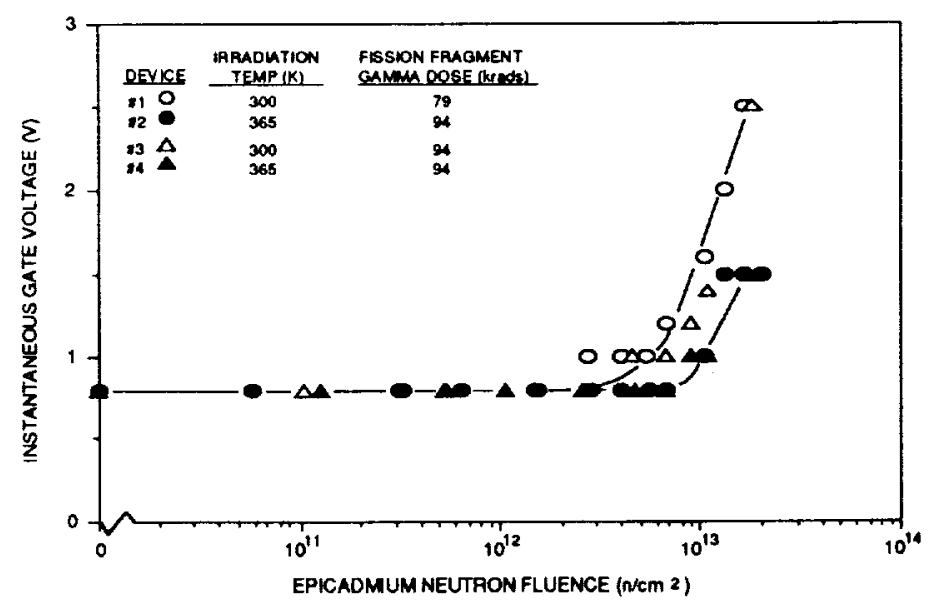

FIG. 5- INSTANTANEOUS GATE VOLTAGE FOR AN INSTANTANEOUS FORWARD CURRENT OF 25 A VERSLS EPICADMUUM NEUTRON FLUENCE FOR PHASE-CONTROL TYPE SILICON CONTROLLED RECTIFIER C 30 (500 V/ 35 A).

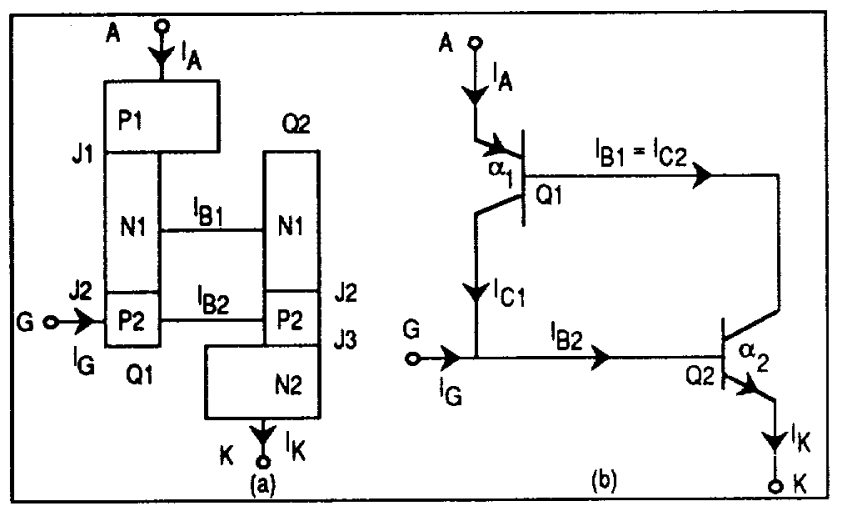

FIG. 2 - TWO TRANSISTOR MODEL OF SCR: (A) BASIC STRUCTURE, (B) EOUIVALENT CIRCUIT.

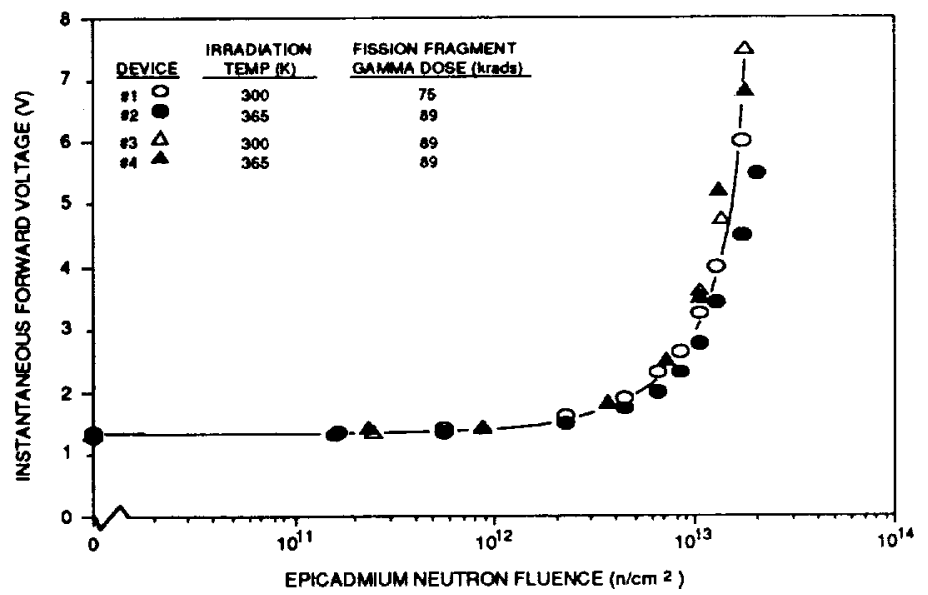

FIG. 4. INSTANTANEOUS FORWARD VOLTAGE AT INSTANTANEOUS FORWARD CURRENT OF 25 A YERSUS EPICADMUM NEUTRON FLUENCE FOR INVERTER TYPE SILICON CONTROLLED RECTFIER 2ORIF 40 W2O $(400 \mathrm{~V} / 32 \mathrm{~A})$.

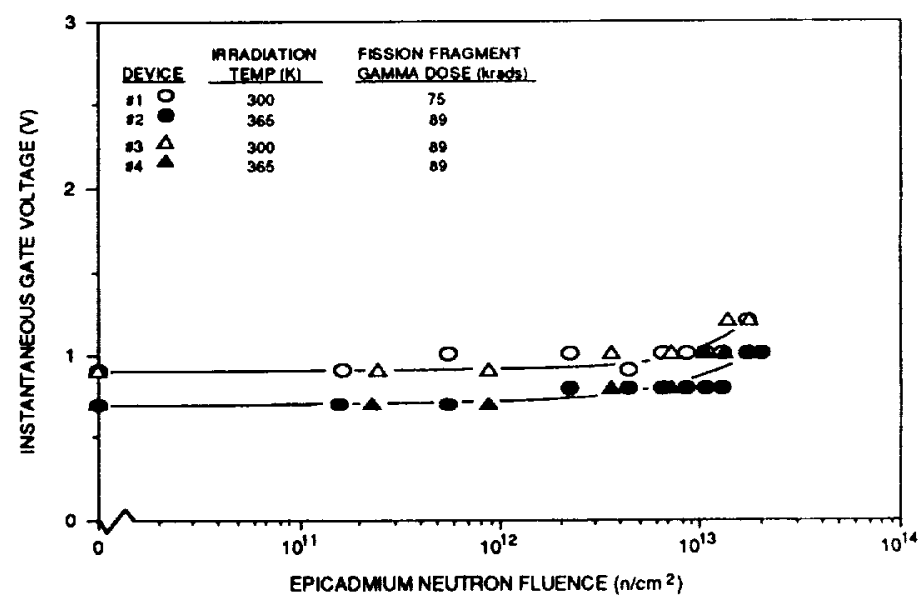

FIG. - INSTANTANEOUS GATE VOLTAGE FOA AN INSTANTANEOUS FORWARD CURRENT OF 25 A VERSUS EPICAONGUM NEUTRON FLUENCE FOA INVERTER TYPE SILICON
CONTROLLED RECTIFIER 2OAIF $40 W 20$ (400 V/32 A). 


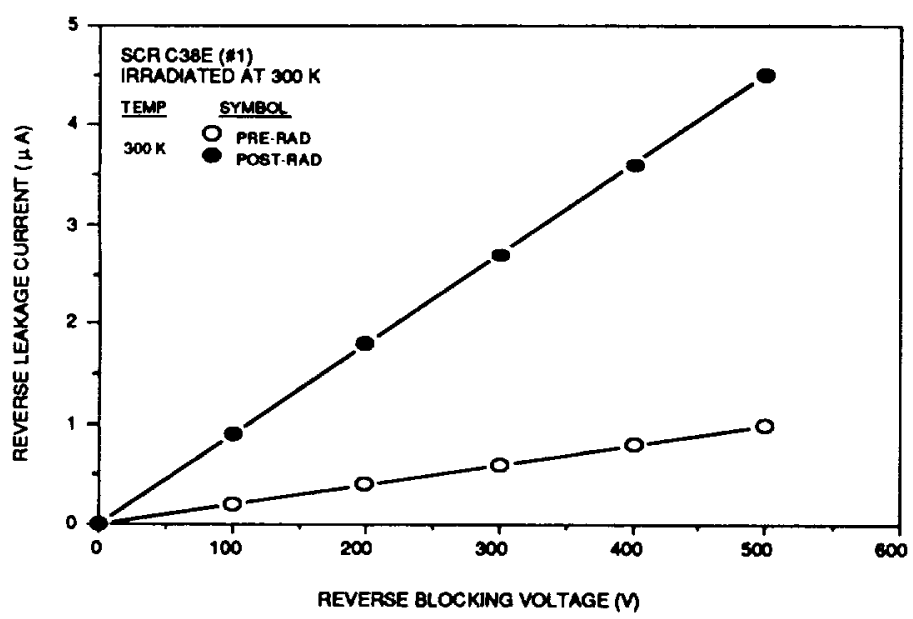

FIG. 7 - PRE-ANO POSTIRRADIATON REVERSE LEAKAGE CUARENT VERSUS REVERSE BLOCKING VOLTAGE FOR SILICON CONTROLLED RECTIFIEA C3QE (500 V/ $35 \mathrm{~A}$ ) NEUTRON FLUENCE - $3.1 \times 10^{13} \mathrm{ncm}$ ? FISSION FAAGMENT GAMMA DOSE $=145 \mathrm{krada}$

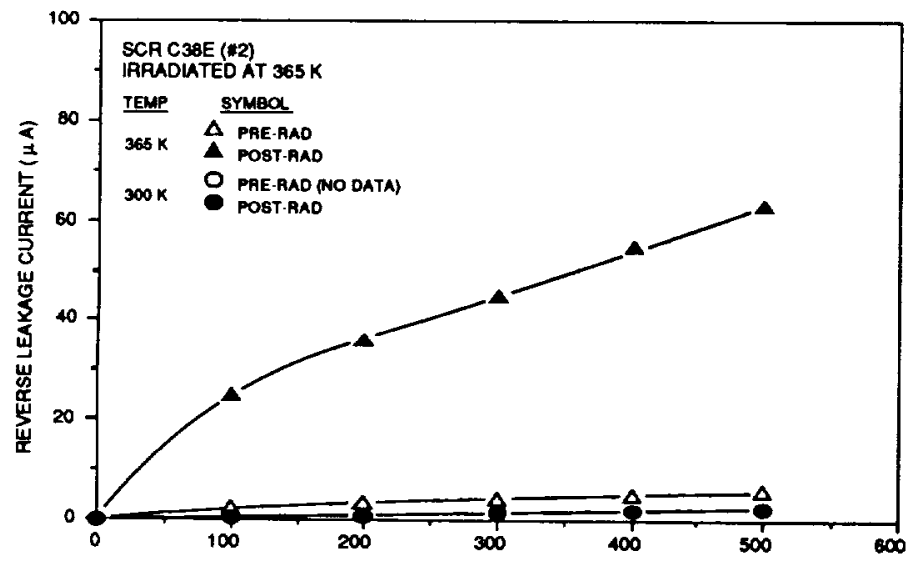

REVERSE BLOCKING VOLTAGE $M$

FIG. 9 - PRE. AND POST-IRRADIATION REVERSE LEAKUGE CURRENT VERSUS REVERSE BLOCKING VOLTAGE FOR SILICON CONTROLLED RECTFIER C $38 E(500 \mathrm{~V} / 35 \mathrm{~A})$ : NEUTRON FLUENCE = $3.1 \times 10^{13} \mathrm{~N} / \mathrm{cm}$ ?. FISSION FPMGMENT GAMMA DOSE = $145 \mathrm{kmd}$

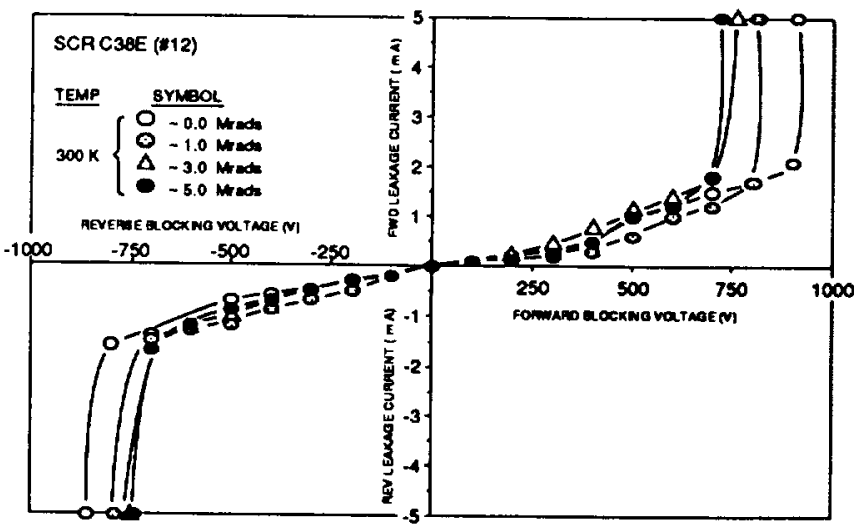

FIG. 11 - FORWARD AND REVERSE LEAKAGE CURRENT VERSUS FORWARD AND CONTROLLED RECTIFIEA C.36E (500 V/35 A): DOSE RATE - $67.3 \mathrm{kradehr}$

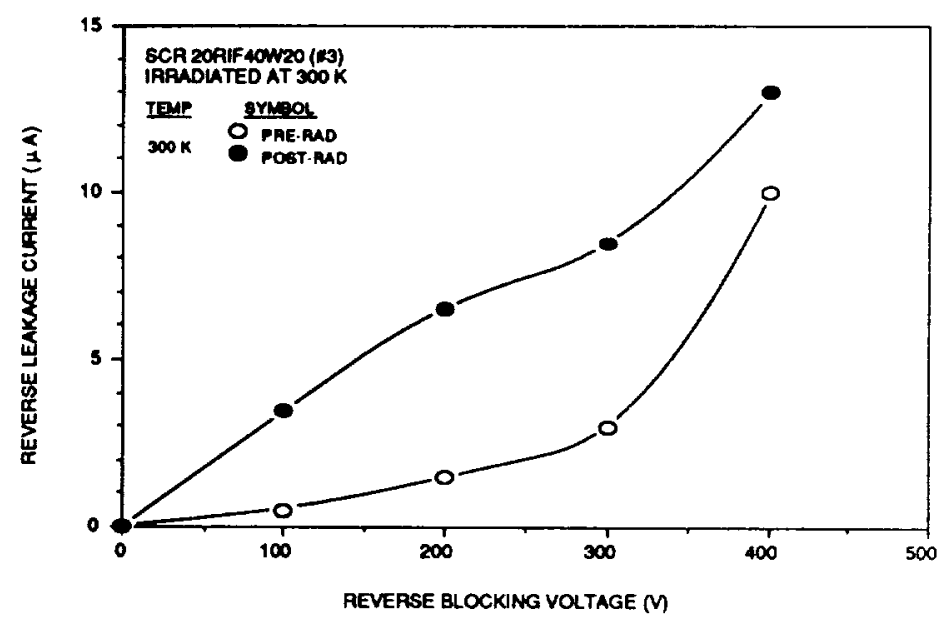

FIG. - - PRE-AND POST-IRRAOLATION REVERSE LEAKAGE CURRENT VERSUS REVERSE BLOCKING VOLTAGE FOA SILICON CONTROLLED RECTIFIER $20 R I F 40$ W20 (400 V/ $32 \mathrm{~A}$ ):
NEUTRON FLUENCE = $3.2 \times 10^{13} \mathrm{n} / \mathrm{cm} 2$, FISSION FRAGMENT GAMMA DOSE = $166 \mathrm{krads}$.

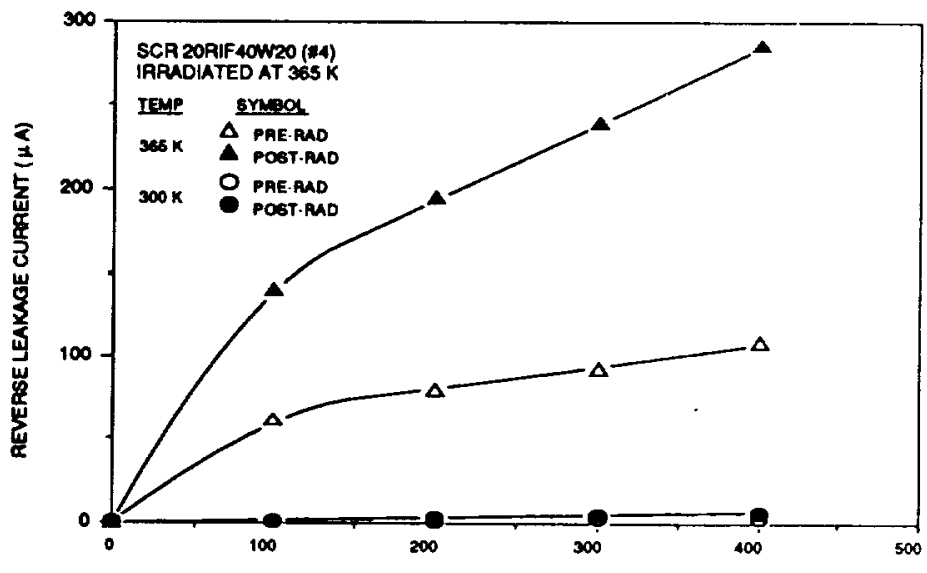

REVERSE BLOCKING VOLTAGE ( $V$ )

FIG. 10. PRE- AND POST-IPRADIATION REVERSE LEAKAGE CURRENT VERSUS REVERSE

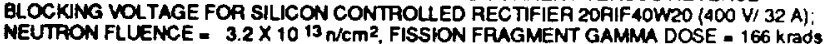

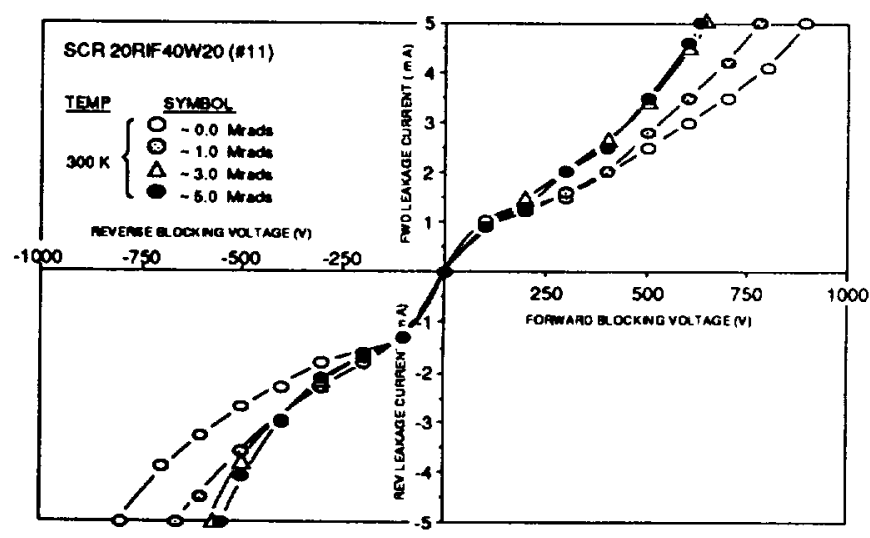

FIG. 12 - FORWARO AND REVERSE LEAKAGE CURRENT VERSUS FORWARD AND REVERSE BLOCKING VOLTAGE, RESPECTIVELY FOR SILICON CONTROLLED RECTFIER 2OAIF 40 W2O (400 V/32 A): DOSE RATE = 67.3 


\section{REPORT DOCUMENTATION PAGE}

Public reporting burden for this collection of information is estimated to average 1 hour per response, including the time for reviewing instructions, searching existing data sources, gathering and maintaining the data needed, and completing and reviewing the collection of information. Send comments regarding this burden estimate or any other aspect of this collection of information, including suggestions for reducing this burden, to Washington Headquarters Services, Directorate tor intormation Operations and Reports, 1215 Jefferson Davis Highway, Suite 1204. Arlington, VA 22202-4302, and to the Office of Management and Budget, Paperwork Reduction Project (0704-0188), Washington, DC 20503.

1. AGENCY USE ONLY (Leave blank 2. REPORT DATE

August 1992 3. REPORT TYPE AND DATES COVERED

Technical Memorandum

\section{TITLE AND SUBTITLE}

Neutron, Gamma Ray, and Temperature Effects on the Electrical Characteristics of Thyristors

6. AUTHOR(S)
5. FUNDING NUMBERS

\section{A.J. Frasca and G.E. Schwarze}

WU $-590-13-31$

7. PERFORMING ORGANIZATION NAME(S) AND ADDRESS(ES)

National Acronautics and Space Administration

Lewis Research Center

Cleveland, Ohio 44135-3191
8. PERForming ORGANIZATION REPORT NUMBER

E-7131
9. SPONSORING/MONITORING AGENCY NAMES(S) AND ADDRESS(ES)

National Aeronautics and Space Administration

Washington, D.C. 20546-0001
10. SPONSORING/MONITORING AGENCY REPORT NUMBER

NASA TM-105728

\section{SUPPLEMENTARY NOTES}

Prepared fier the 27 h Intersocicty Encrgy Conversion Enginecring Conference cosponsored by SAE, ACS, AIAA, ASME, IEEE, NIChE, and ANS, San Dicgo, California, August 3-7, 1992. A.J. Frasca, Wittenberg University, Springfield, Ohio 45501, and G.E. Schwarze, NASA Lewis Research Center. Cleveland, Ohio. Responsible person, G.E. Schwarze, (216) 433-6117.

12a. DISTRIBUTION/AVAILABILITY STATEMENT

12b. DISTRIBUTION CODE

Unclassified - Unlimited

Subject Category 33

\section{ABSTRACT (Maximum 200 words)}

Experimental data showing the effects of neutrons, gamma rays, and temperature on the electrical and switching characteristics of phase-control and inverter-type SCRs are presented. The special test fixture built for mounting, heating, and instrumenting the test devices is described. Four SCRs were neutron irradiated at $300 \mathrm{~K}$ and four at $365 \mathrm{~K}$ for fluences up to $3.2 \times 10^{13} \mathrm{n} / \mathrm{cm}^{2}$, and eight were gamma irradiated at $300 \mathrm{~K}$ only for gamma doses up to 5.1 Mrads. The electrical measurements were made during irradiation and the switching measurements were made only before and after irradiation. Radiation induced crystal defects, resulting primarily from fast neutrons, caused the reduction of minority carrier lifetime through the generation of $\mathrm{R}-\mathrm{G}$ centers. The reduction in lifetime caused increases in the on-state voltage drop and in the reverse and forward leakage currents, and decreases in the turn-off time.

\section{SUBJECT TERMS}

Radiation effects; Radiation damage; Solid state switch; Semiconductor switch; Thyristor; SCR; Temperature annealing; Power conditioning

\begin{tabular}{|c|c|}
\hline $\begin{array}{c}\text { 17. SECURITY CLASSIFICATION } \\
\text { OF REPORT } \\
\text { Unclassified }\end{array}$ & $\begin{array}{c}\text { 18. SECURITY CLASSIFICATION } \\
\text { OF THIS PAGE } \\
\text { Unclassified }\end{array}$ \\
\hline
\end{tabular}

19. SECURITY CLASSIFICATION OF ABSTRACT

Inclesified
15. NUMBER OF PAGES 8

16. PRICE CODE A02

20. LIMITATION OF ABSTRACT 